\title{
MOSFETs used in ideal diode circuits for Lundell alternator rectifiers
}

\author{
Alex Van den Bossche \\ EELAB Ghent University \\ Technologiepark 913 \\ 9052 Gent Belgium \\ Email: Alex.VandenBossche@ugent.be
}

\author{
Salim Haddad \\ Département de génie mécanique \\ Université 20 août 1955 \\ Skikda Algeria \\ Email: s.haddad@univ-skikda.dz
}

\author{
Dimitar Petrov \\ Vencislav Valchev \\ Department of Electronics \\ Technical University of Varna \\ Email: muta4eto9303@gmail.com \\ vencivalchev@hotmail.com com
}

\begin{abstract}
Low voltage power applications suffer from losses in diode voltage drops. For example, the Lundell car alternator has a low efficiency, partly due to a highcurrent diode voltage drop of $1.1 \mathrm{~V}$, being $2.2 \mathrm{~V}$ in a bridge configuration, resulting in $15 \%$ of output voltage and corresponding losses. Schottky diodes have a lower drop, but are quite fragile and seem not to be preferred in that application. This paper proposes a two terminal circuit with a MOSFET, which emulates a diode while having a very low voltage drop. The main item is that the MOSFET is turned on at a small negative drain-source voltage. This could be done using an op-amp circuit, but the used transistor array circuit can have a lower current consumption. At full load, some $73 \%$ voltage drop reduction is possible, for example while using a MOSFET of max. $0.003 \mathrm{ohm}$ on-resistance at $125^{\circ} \mathrm{C}$, hence the voltage drop at $100 \mathrm{~A}$ can be limited to $0.3 \mathrm{~V}$. At a rather typical 30A DC-current load, some 87\% voltage drop reduction is possible, $100 \mathrm{mV}$ drop compared to $0.8 \mathrm{~V}$ for a diode. The solution costs hardly more than the usual "press-fit" diodes. The circuit has a short paid back time by the lower use of aluminum for the heat sink and the fuel saving. In a large quantity such a MOSFET can cost less than 0.5 Euro, and the cost of the circuit is not larger.
\end{abstract}

Keywords-ideal diode; energy saving; automotive; Lundell alternator; synchronous rectifying.

\section{INTRODUCTION}

Although 48V systems are proposed now, still a lot of $12 \mathrm{~V}$ circuits exist, but even $48 \mathrm{~V}$ systems carry similar currents as the power requirements did increase as well. The reason is that, in start-stop systems also some braking energy is recovered and that in mild hybrids, some city traffic and also automatic parking can be done with it. The maximum DC output current of a Lundell alternator can be 100 A or even more, with an efficiency hardly exceeding $50 \%$ [1],[2]. The delivered voltage is about $14 \mathrm{~V}$ at the terminals, to get some $13.8 \mathrm{~V}$ at the battery. At a $2.2 \mathrm{~V}$ diode bridge drop, about $15 \%$ of the output power is lost in the diode bridge. Usually press-fit normal diodes or Zener diodes are used in the rectifier bridge. Zener diodes are used to act as a "load-dump" if the battery is disconnected, but they have even more voltage drop in the forward direction than usual rectifier diodes. Normally, Schottky diodes could reduce losses, but large Schottky diodes are quite sensitive to local hot spots that may destroy them. In large size Schottky diodes, manufacturers have to add resistivity in the silicon to equalize the current density; this resistivity reduces a part of the benefit. A solution is using a MOSFET instead, that is turned on whenever the drainsource voltage gets negative. MOSFETs in the conduction mode do not show hot spot problems, as the channel has a positive temperature coefficient. It is an advantage if the stand by current is very low, so that the battery is not discharged by it. It is an additional advantage if the circuit only has two connections and does not need an auxiliary supply. Solutions have been proposed using only two driving transistors, but the estimate is a current drain for 6 transistors of $900 \mathrm{~mA}$, this would empty a 30Ah battery in 33 hours [3]. Other circuits use about $1 \mathrm{~mA} / \mathrm{ideal}$ diode in stand-by mode, but are only good for battery swapping, so static switches [4]. Some IC's exist with an internal charge pump, such as LTC4357 [5], giving a consumption of $3 \mathrm{~mA}$ for a bridge, or about 5mA for a faster one LTC4218 [6]. In the proposed topology, there is no current in standby mode (only a few $\mu \mathrm{A}$ component leakage), so even a lower leak current than Schottky diodes, and about $0.1 \mathrm{~mA}$ current drain/internal supply due to resistors. So, the proposed circuit does not reduce the self-discharge time of the battery.

\section{PROPOSED TOPOLOGY AND CIRCUIT}

Synchronous rectifying is widely used in other types of switched mode circuits [7]. In alternators some circuits propose the use of a reference diode, compared to the voltage of a drain sensing diode and a differential amplifier to control MOSFETs [8], or a lot of circuitry is used [9]. The gate driving can indeed be done by an opamp, but if it has to sink at least some $50 \mathrm{~mA}$, it often draws $2 \mathrm{~mA}$ or more from its supply in standby. A current of $2 \mathrm{~mA}$ during for example $20 \mathrm{~ms}$ is $40 \mu \mathrm{C}$, this charge 
would require electrolytic capacitors in the supply. However, it is good to avoid electrolytic capacitors for reasons as lower cost, wider temperature range and a longer lifetime [10]. A topology using transistors is proposed in Fig.1, where the functionality is rather easy to understand. A sensing diode D1 senses the drain-source voltage, and is compared to the base of Q2 to drive the MOSFET Q1 using Q3 and D2. The capacitor C2 and the Zener diodes Z1 and Z2 create a charge pump. R1 and R2 can be as high as $220 \mathrm{~K}$. Note that, when the alternator is not used, the circuit draws no current by the use of $\mathrm{C} 2$. Thus, only leakage currents from the power transistors remain that are typically below $1 \mu \mathrm{A}$ at ambient temperature, so much less than using Schottky diodes of the same current rating. Note that there is a minimum frequency and a minimum voltage for a good operation. A problem in voltage sensing is that the diode voltage drop is typically higher than a base-emitter voltage drop. A solution is to implement also the "diode function" with transistors. After a few tests, it has been seen that the baseemitter voltage of a linear working bipolar transistor is very close to the base collector voltage when the baseemitter is short-circuited. It is not widely known, but it uses the fact that an emitter-base connection lowers the voltage of the base-collector diode voltage drop. The reason is that it acts as a reverse conducting NPN, so that the base current is lowered. The collector-base diode with short-circuited base-emitter withstands the full rated voltage of a bipolar transistor. Dual transistors exist in 6 pin packages and hence are matched in temperature. Using dual transistors reduces also the component count and possible polarity errors when using diodes. A small current is drawn in the on-state by $\mathrm{R} 1$, and in the off state by $\mathrm{R} 1$ and R2; it can be kept under $0.2 \mathrm{~mA}$ at $10 \mathrm{~V}$ supply. A scheme using dual transistors is given in Fig. 2. It has almost the same functionally but at improved performance. As a matched transistor is used as a diode, the voltage sense is at about $20-50 \mathrm{mV}$ negative drain source voltage. The component sizing has been done for a $14 \mathrm{~V}$ alternator and a minimum of $50 \mathrm{~Hz}$, so this would correspond with $500 \mathrm{rpm}$ for a 12 pole Lundell alternator. In practice the alternator runs 1.2-1.5 times faster than the engine. This fact is not a limitation, as below that speed the peak EMF is lower than the battery voltage.

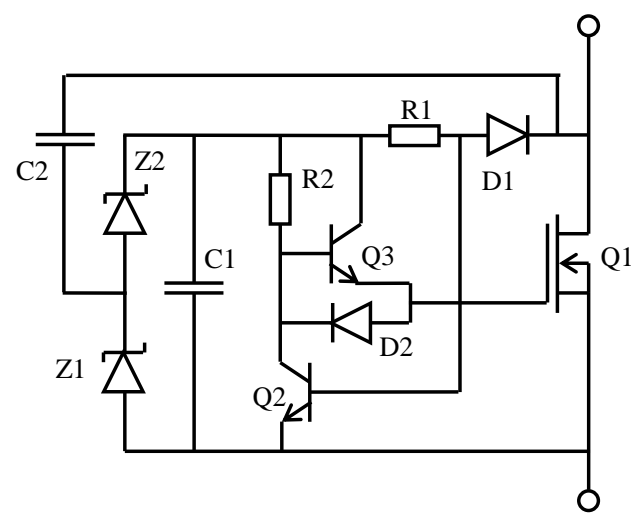

Fig. 1: Principle scheme of an ideal diode. Z1, Z2: 15V, C1, C2: $1 \mu \mathrm{F}$, R1,R2: 220K, Q1: IRFB7440PBF, Q2,Q3,D1,D2: BC846BDW

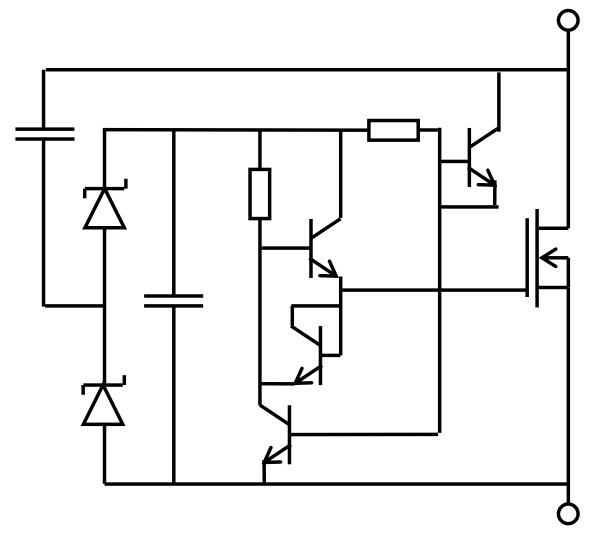

Fig. 2: Circuit using dual transistors: 11 components, but only 5 different types, 9 packages.

\section{PRACTICAL LAY-OUT}

The figures 3 and 4 show the lay-out. The legs of the transistor and the contacts can be soldered in such a way that the high current goes directly to the transistor leads and the gate pin is shortened.

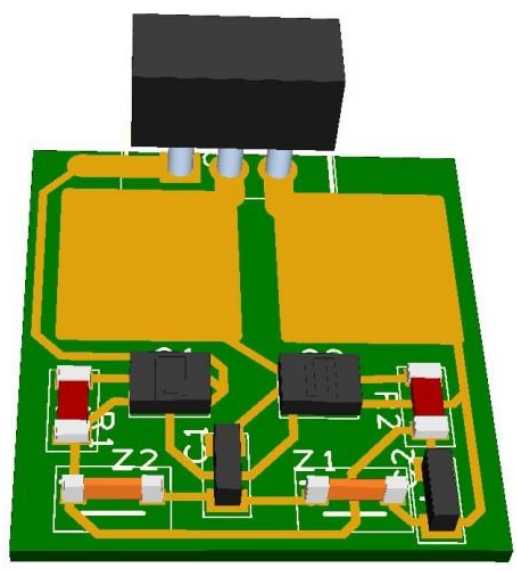

Fig. 3: PCB components 


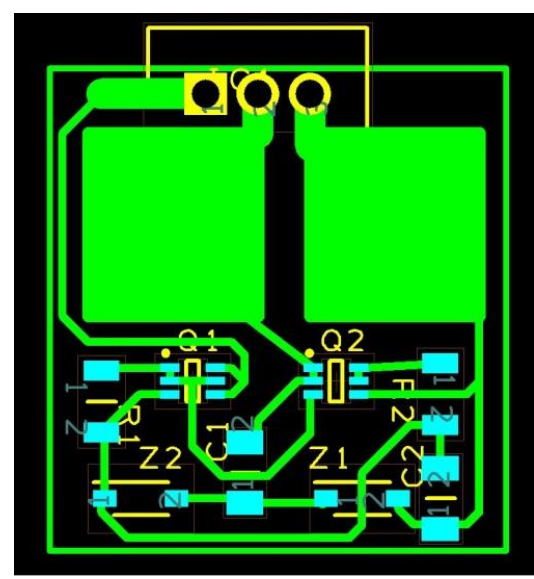

Fig. 4: PCB lay-out

Quite high current MOSFETs exist in a classic TO220 package that can be cooled as well, and their power contacts can be made very close to the wires.

\section{MEASUREMENTS WITHOUT CONNECTED DRAIN}

A functional testing of the PCB can be done without large current trough the transistor. A sine wave of $14 \mathrm{~V}$ peak-peak is put at the Drain-Source contacts, but where the drain is not connected. The $14 \mathrm{~V}$ is the same peak-peak voltage as the alternator with regard to the charging the internal supply. It is an easy functional test method for the PCB. Fig. 5 shows a gate voltage at $50 \mathrm{~Hz}$, with transistor where only the gate-source is connected. The gate source capacitance has a total charge of $100 \mathrm{nC}$

(IRFB7440GPBF, a 120 A transistor used as a load).

The gate voltage drops a bit at the end of the $10 \mathrm{~ms}$ on-time, but it is acceptable. This shows that the capacitors are large enough for the $50 \mathrm{~Hz}$ case.

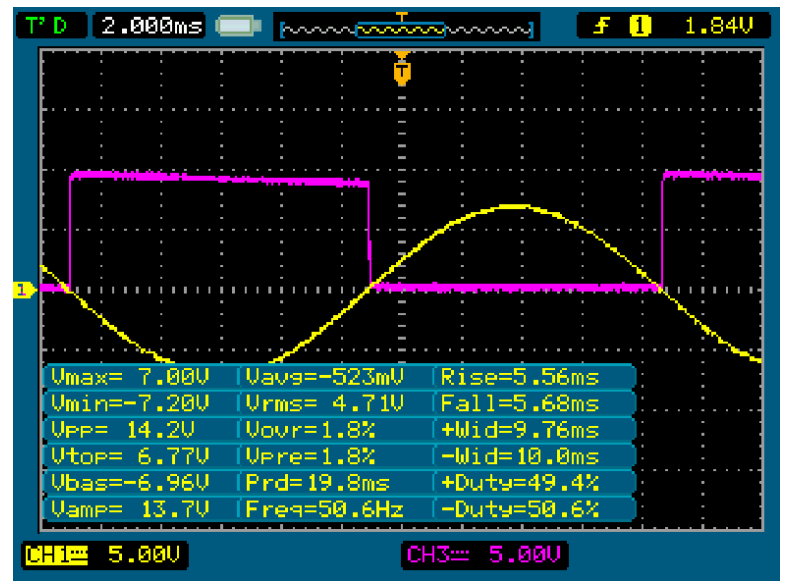

Fig. 5: CH3: Vgs, using a sine wave voltage applied at the DS contacts $(\mathrm{CH} 1)$, without connected drain, $50 \mathrm{~Hz}$.
In Fig 6, a $1 \mathrm{kHz}$ operation is shown, the gate is still fast enough, that means a correct sizing of the resistors. The gate voltage is a bit higher, and does not show some drop compared to the $50 \mathrm{~Hz}$ case, as the time to discharge the internal supply capacitor is shorter. The advantage of the above measurement technique is being able to check the functionality and the frequency range without having to inject heavy currents, but the applied negative voltage should not be lower than $-7 \mathrm{~V}$ to avoid an emitter-base breakdown to occur. The method is also an advantage to test PCBs in production without having to have a permanent set-up with heavy currents. Note that the frequency range can be increased by lowering the resistances in the circuit, but then the capacitors have to be increased to cope also with the lower frequencies.

\section{MEASUREMENTS WITH TRANSISTORS TESTED AT A LARGER CURRENT}

The paper is based on an Erasmus student mobility and has not a large budget (financially and in time). A full load measurement set-up with an alternator in a car would take too much time and budget. A simpler set-up has been made with a transformer. A peak to peak voltage of $14 \mathrm{~V}$ has been applied, which is normal in diode of car alternators. In order to check the voltage drop at higher current, a set-up has been made with a variable transformer and a fixed step down higher current transformer. Two "ideal diodes" have been made and to assemble a full bridge they have been put in parallel to an existing 35 A bridge. It has been also observed that an "ideal diode" heats much less than the diodes from the classic bridge. The tests have been made with a peak

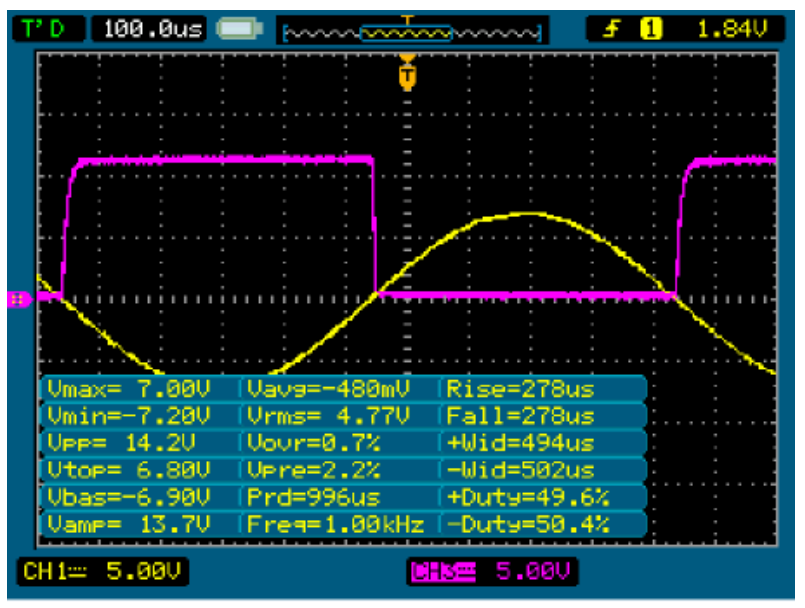

Fig 6: Same as Fig 5, but $1000 \mathrm{~Hz}$, 


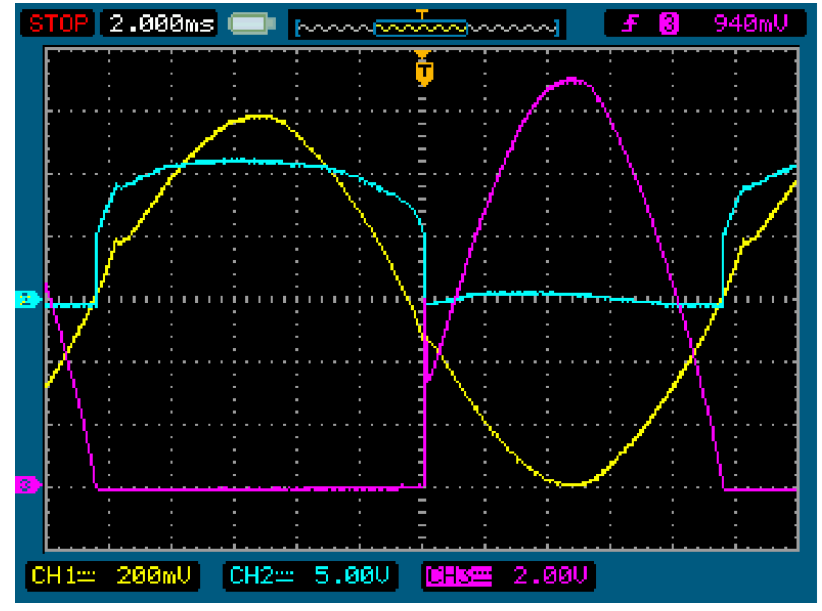

Fig. 7: CH1: 20A/div, CH2:Vgs, CH3: full Vds curve at 2V/div

current of 30A. The gate, drain-source and AC current are shown in Fig 7. Fig. 7 shows the full $V d s$ curve, whereas Fig. 8 shows the $V d s$ at $0.5 \mathrm{~V} / \mathrm{div}$, so magnified, to show the voltage drop of about $0.1 \mathrm{~V}$ at $30 \mathrm{~A}$.

whereas Fig. 8 shows the Vds at $0.5 \mathrm{~V} /$ div, so magnified, to show the voltage drop of about $0.1 \mathrm{~V}$ at $30 \mathrm{~A}$.

A magnified $V d s$ at $0.5 \mathrm{~V} / \mathrm{div}$ is shown in Fig; 7, we checked that at a lower V/div: the oscilloscope is overloaded. As far as can be seen $0.1 \mathrm{~V}$ drop is obtained at $30 \mathrm{~A}$, corresponding with $3.3 \mathrm{~m} \Omega$, whereas the transistor is sold for $<2.5 \mathrm{~m} \Omega$ at $25^{\circ} \mathrm{C}$. So, it corresponds to what could be expected. To be sure to have only the voltage drop without contact resistance, the voltage was measured directly on the legs. It can be seen that some minor effect of the drain-gate Miller capacitance is present during the off state: small fluctuations are possible within tand $-0.7 \mathrm{~V}$, but do not harm the functionality.

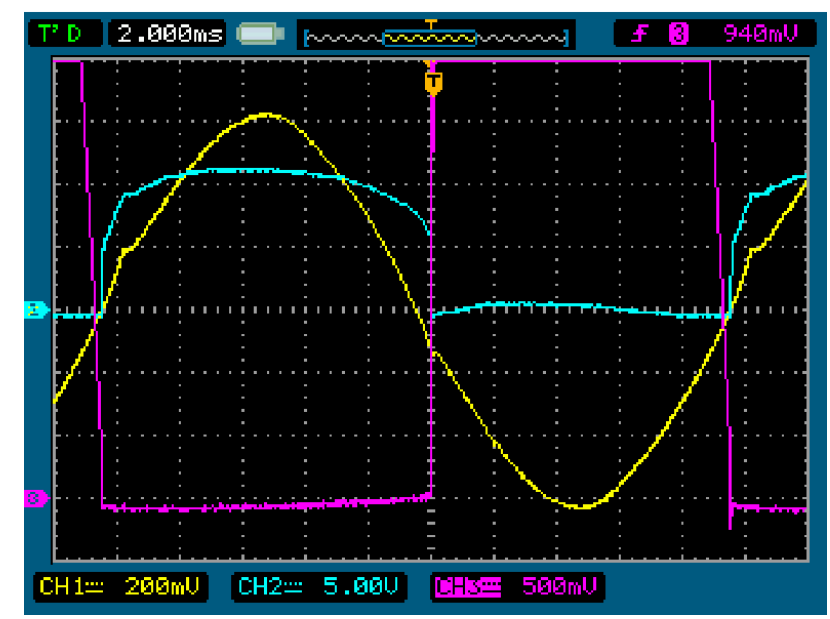

Fig. 8: $\mathrm{CH} 1: 20 \mathrm{~A} / \mathrm{div}, \mathrm{CH} 2$ : Vgs, $\mathrm{CH} 3$ : magnified Vds curve at $0.5 \mathrm{~V} / \mathrm{div}$

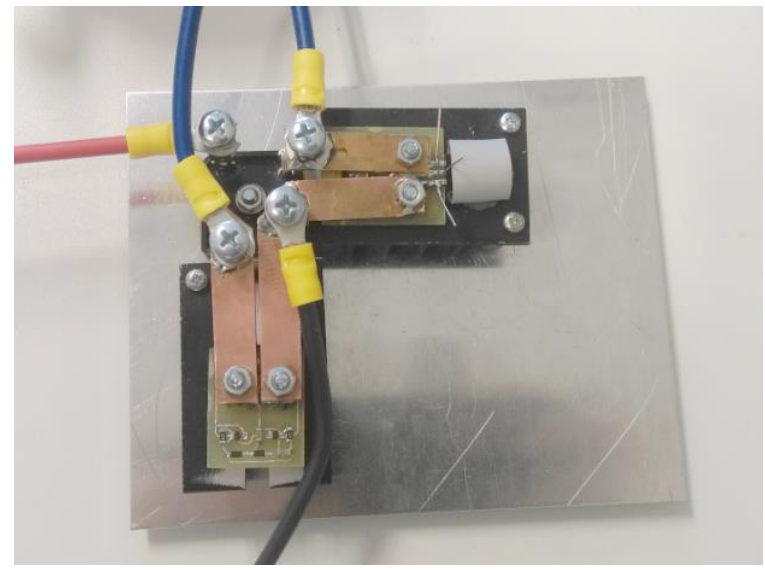

Fig. 9: Test set-up, with two "ideal diodes" inserted in parallel on a bridge.

A good lay-out of the circuit is needed to realize the low voltage drop throughout the circuit. Fig. 9 shows the test set-up.

Two "ideal diodes" are put in parallel on a 35A rectifier bridge. The rectifier bridge is used as a mounting support and to deliver the remaining two diodes to make a full bridge. The transistor upper right has measuring pins.

\section{EVALUATION OF BENEFIT}

Own measurements show that today cars need some 10-11 A to run at idle and some 30 A with light loads such as a fan, and headlamps. At 30A the voltage drop is about $100 \mathrm{mV} /$ diode or $200 \mathrm{mV}$ total, which could be compared with $0.8 \mathrm{~V}$ in normal diodes at that current, which is not full load. Some $48 \mathrm{~W}$ can be saved at the output side. This corresponds to about $80 \mathrm{~W}$ at the mechanic side (about $60 \%$ efficiency from mechanic to AC). A typical efficiency of an internal combustion engine is $20 \%$, so 400W less thermal has to be delivered by the fuel. At an average speed of $50 \mathrm{~km} / \mathrm{h}, 2 \mathrm{~h}$ is needed for $100 \mathrm{~km}$. It corresponds to $800 \mathrm{Wh}$ fuel and this is $0.08 \mathrm{Liter} / 100 \mathrm{~km}$. For $100000 \mathrm{~km}$ it corresponds to 80 liter of fuel saving. This fuel saving doubles if the same $100000 \mathrm{~km}$ is done in a city where the typical speed would be $25 \mathrm{~km} / \mathrm{h}$, corresponding to 160 liter of fuel saving.

A good estimate of the BOM of the components is given in table I. For comparison, the price of a costeffective press-fit diode: ZQ50A Diode for $12 \mathrm{~V}$ Alternator, $30000+$ is $0.3 \$$ FOB (x6). The MOSFET solution needs a PCB, but much less aluminum to cool that partly compensates costs. It is estimated that there would be about 5.5 euro BOM difference for the whole bridge. 
TABLE 1: BILL OF MATERIALS FOR LARGE QUANTITIES

\begin{tabular}{|c|c|c|c|}
\hline component & number & price high Qy & supplier high Qy \\
\hline $\begin{array}{c}\text { IRFB7440GPB } \\
\text { F }\end{array}$ & 1 & $\begin{array}{c}25000 \text { pieces: } \\
0,428 € / \text { piece }\end{array}$ & $\begin{array}{c}\text { Mouser } \\
\text { 942-IRFB7440GPBF }\end{array}$ \\
\hline BC846BDW1 & 4 & $\begin{array}{c}99000 \\
0.02 € / \text { piece }\end{array}$ & $\begin{array}{c}\text { Mouser } \\
863-B C 846 B D W 1 T 1 G\end{array}$ \\
\hline 220K resistor & 2 & 100000 & Mouser \\
& & $0,002 €$ & $\begin{array}{c}\text { 603-RC1206JR- } \\
\text { 07220KL }\end{array}$ \\
\hline 15V Zener & 2 & $20000+$ & Farnell \\
& & $0,026 €$ & MMSZ5245B \\
\hline 470nF cap & 2 & 30000 & Farnell \\
& & $0,0141 €$ & MCT1206R474KCT \\
& & & 2629531 \\
\hline total & 11 & $0.592 € \mathrm{x} 6$ & \\
\hline
\end{tabular}

Even when benefit from and additional costs from production to customer are considered, the cost difference is very low compared to the expected fuel saving (and the corresponding $\mathrm{CO} 2 \ldots$ ). Most of design changes cost more to save a similar amount of fuel.

\section{CONCLUSION}

Using MOSFETs in ideal diode circuits is possible and cost effective; the additional costs are very low compared to the fuel savings and the impact of $\mathrm{CO} 2$ reduction. The advantage of the proposed circuit is that it appears as a two-wire solution to emulate a diode, which makes it simple to implement. It can be realized without electrolytic capacitors, resulting in a longer life and better temperature resistance than other possible solutions. The current consumption when the engine is shut down is mainly the transistor leakage current, which is lower than a corresponding Schottky diode of the same rating, so no significant battery self-discharge is expected. The design, as shown, was intended for a frequency above $50 \mathrm{~Hz}$ and below $1 \mathrm{kHz}$. It may be used in other applications as well.

\section{ACKNOWLEDGMENT}

The authors thank the European Erasmus student mobility program and the goodwill of the colleagues.

\section{REFERENCES}

[1] D.M. Whaley, W.L. Soong and N. Ertugrul, Extracting more power from the Lundell car alternator, AUPEC 2004, 26-29 September 2004, Brisbane, Australia, 2004, 6p.

[2] Ruben Ivankovic, Jérôme Cros, Mehdi Taghizadeh Kakhki, Carlos A. Martins and Philippe Viarouge, New Advances in Vehicular Technology and Automotive Engineering, Ch 6, www.intechopen.com, ISBN 978-953-51-0698-2, August 1, 2012.

[3] http://jiggerjuice.info/electronics/projects/power/idealdiode.html

[4] http://solarbotics.net/library/circuits/misc_switching.html

[5] www.linear.com/product/LTC4357

[6] www.linear.com/product/LTC4218

[7] Steve Mappus, Synchronous Rectification for Forward Converters, Fairchild Semiconductor Power Seminar 20102011, pp.1-18.

[8] Alfred Goerlach, Markus Baur, Gleichrichterschaltung WO 2009077257 A1, 2007.

[9] Bruno Charles Nadd, Xavier de Frutos, Andre Mourrier, Method and apparatus for driving a power MOS device as a synchronous rectifier, US7183834, 2003.

[10] Alex Van den Bossche UGent, Salim Haddad and Mourad Mordjaoui (2017) "Power electronic converters without electrolytic capacitors", 5th European Conference on Renewable Energy Systems, Sarajevo, Bosnia and Herzegovina. In European Conference on Renewable Energy Systems p.1-7. 